\title{
Self-Reported Urinary Continence Outcomes for Repeat Midurethral Synthetic Sling Placement
}

\author{
Jonathan A. Eandi, Stacy T. Tanaka, Nicholas J. Hellenthal, R. Corey O'Connor, Anthony R. \\ Stone
}

Department of Urology (JAE, STT, NJH, ARS), UC Davis Medical Center, Sacramento, California, and Department of Urology (RCO), Medical College of Wisconsin, Milwaukee, Wisconsin, USA

\begin{abstract}
Objective: To evaluate our experience with tension-free transvaginal tape (TVT) placement for the management of stress urinary incontinence (SUI) in women who had previously undergone a failed midurethral synthetic sling (MUS) procedure.

Materials and Methods: Ten women underwent retropubic TVT insertion for continued or recurrent SUI following a prior MUS procedure. No attempt was made to remove the previously placed sling at the time of surgery. A retrospective chart review was performed to obtain perioperative and follow-up patient information. Post-operatively, each patient completed a mailed incontinence questionnaire to assess self-reported urinary continence outcomes.

Results: All 10 women were available for follow-up at a mean period of 16 months (range 6 to 33 ). Four of the 10 patients achieved complete continence, and another three patients reported significantly improved continence and quality of life. Three women stated that their continence did not improve.

Conclusions: TVT placement may be a viable option for the management of women with persistent or recurrent SUI following an initial MUS procedure.
\end{abstract}

Key words: female; urinary incontinence; stress urinary incontinence; prostheses and implants; slings Int Braz J Urol. 2008; 34: 336-44

\section{INTRODUCTION}

Tension-free transvaginal tape (TVT) is one of the preferred therapeutic approaches for the treatment of female stress urinary incontinence (SUI). It is considered a minimally invasive yet effective surgical method for the management of SUI. Recently published TVT surgical results show a high success rate ranging from $80-95 \%$ with greater than five year follow-up (1-4). However, 5-20\% of treated patients experience surgical failure with clinically significant recurrent or persistent SUI (1-3).
To date, no consensus exists for the management of SUI in women with a previous failed midurethral synthetic sling (MUS) procedure. Several possible treatment options have been described in the literature. These include pelvic floor rehabilitation, placement of an artificial urinary sphincter $(5,6)$, periurethral injection of bulking agents (6), or most commonly a more invasive anti-incontinence surgery such as colposuspension or suburethral sling (6-8). Recently, some authors have advocated transvaginal shortening or tightening of the implanted tape for recurrent or persistent SUI after MUS (9-12). Another 
option is to perform a repeat MUS. However, there is a paucity of published data on repeat MUS procedures for the management of persistent or recurrent SUI $(10,13-16)$.

We describe our experience with retropubic TVT placement for the management of SUI in women with a previous failed MUS procedure. In this study we utilized a patient self-reported quality of life questionnaire to assess the efficacy of the procedure. To our knowledge, this is the first study to present data using a validated incontinence questionnaire to assess outcomes for TVT insertion following an unsuccessful MUS procedure.

\section{MATERIALS AND METHODS}

Following institutional review board approval, a retrospective chart review was performed to identify women that underwent placement of a TVT due to primary or recurrent failure of a MUS surgery for the management of SUI. A total of ten women (mean age 65 years, range 43 to 80 ) underwent retropubic TVT insertion at our institution between January 2004 and June 2006 following failure of a previously placed MUS. All procedures were performed by, or under the guidance of one experienced pelvic surgeon (A.R.S.). Preoperative evaluation included previous medical history, physical examination, urinalysis, urine culture, and video urodynamic evaluation. No patient had evidence of tape extrusion or erosion. Post-operatively, each participant received a telephone call from a non-biased third party informing them of the study prior to mailing of the International Consultation on Incontinence Questionnaire (ICIQ) (Appendix-1) (16). The questionnaires were accompanied by an informed consent as well as a brief outline describing the objective of the study. All ten patients completed and returned the consent and questionnaire forms. Complete continence was defined by a sum score of zero on the ICIQ. In other words, the patient was required to self-report total absence of urinary leakage to qualify as completely continent. We defined a score of 0 or 1 , on a scale from 0 to 10 , on question 3 of the ICIQ to indicate that urine leakage no longer impacted the patient's quality of life.
We have occasionally used periurethral bulking agents after TVT failure, however this paper focuses on those patients who underwent repeat TVT.

Retropubic midurethral synthetic sling placement was performed using the Gynecare (Ethicon, Somerville, NJ) TVT device. No attempt to locate or alter the previously placed sling was made at the time of surgery.

\section{RESULTS}

Placement of the TVT was performed in 10 patients following an initial unsuccessful MUS procedure (Table-1). The interval between the first MUS and second TVT procedure ranged from three to 32 months (average 14). All 10 women were available for follow-up at a mean period of 16 months (range 6 to 33). Five women underwent previous retropubic MUS, or TVT. The remaining five patients underwent a prior transobturator tape (TOT), including four using the in-to-out technique and one using the out-to-in method. Four patients underwent incision or removal of the initial MUS for voiding dysfunction. Three of these women had previously undergone TVT, the other underwent TOT, and required clean intermittent catheterization following the first procedure.

All ten patients demonstrated urodynamic evidence of SUI following original MUS placement prior to undergoing the second TVT procedure. The Valsalva leak point pressure was $<60 \mathrm{~cm} \mathrm{H}_{2} \mathrm{O}$ in three women. None had significant detrusor overactivity, although anticholinergics were used for subjective urgency. Physical examination confirmed the presence of genuine stress incontinence in all patients. All had some degree of urethral hypermobility.

At the time of TVT insertion, two women underwent concurrent procedures. One patient required anterior repair with porcine graft, while another underwent posterior repair. Both patients were discharged home on post-operative day one without a catheter in place. The eight patients who underwent TVT placement alone were all discharged home on the same day of surgery. Average blood loss and operative time for these eight patients was $10 \mathrm{~mL}$ (range 5 to 20) and 30 minutes (range 24 to 42), respectively. Including the two women who underwent additional surgery (one anterior repair, one posterior repair), the mean blood 
Table 1 - Patient information.

\begin{tabular}{|c|c|c|c|c|c|c|c|c|c|c|c|}
\hline $\mathbf{N}$ & $\begin{array}{l}\text { Age } \\
\text { (years) }\end{array}$ & $\begin{array}{c}\text { Type } \\
\text { of } \\
\text { MUS } \\
\text { 1st } \\
\text { Surgery }\end{array}$ & $\begin{array}{c}\text { 1st } \\
\text { Surgery } \\
\text { Other } \\
\text { Proce- } \\
\text { dures }\end{array}$ & $\begin{array}{c}\text { Time } \\
\text { from } \\
1 \text { st } \\
\text { Surgery } \\
\text { to MUS } \\
\text { Incision } \\
\text { (months) }\end{array}$ & Antichol & $\begin{array}{c}\text { VLPP } \\
\text { before } \\
\text { 2nd } \\
\text { Surgery } \\
(\mathrm{cm} \\
\left.\mathrm{H}_{2} \mathrm{O}\right)\end{array}$ & $\begin{array}{c}\text { Type } \\
\text { of } \\
\text { 2nd } \\
\text { MUS }\end{array}$ & $\begin{array}{l}\text { Time } \\
\text { from } \\
\text { 1st to } \\
\text { 2nd } \\
\text { Surgery } \\
\text { (months) }\end{array}$ & $\begin{array}{c}\text { 2nd } \\
\text { Surgery } \\
\text { Other }\end{array}$ & $\begin{array}{l}\text { Post-op } \\
\text { Antichol }\end{array}$ & $\begin{array}{c}\text { Follow-up } \\
\text { (months) }\end{array}$ \\
\hline 1 & 68 & TOT & $\begin{array}{l}\text { ant/post } \\
\text { repair }\end{array}$ & N/A & yes & $60-100$ & TVT & 4 & none & no & 6 \\
\hline 2 & 43 & TOT & none & 15 & yes & $>100$ & TVT & 18 & none & yes & 11 \\
\hline 3 & 69 & TVT & none & 4 & no & $60-100$ & TVT & 11 & $\begin{array}{l}\text { ant } \\
\text { repair }\end{array}$ & no & 11 \\
\hline 4 & 70 & TVT & $\begin{array}{l}\text { post } \\
\text { repair }\end{array}$ & 1 & no & $>100$ & TVT & 17 & none & no & 18 \\
\hline 5 & $80 * *$ & TVT & none & N/A & yes & $<60$ & TVT & 32 & none & yes & 21 \\
\hline 6 & 49 & TOT & none & N/A & yes & $<60$ & TVT & 3 & none & no & 22 \\
\hline 7 & $70 * *$ & TOT & none & N/A & no & $60-100$ & TVT & 6 & none & no & 31 \\
\hline 8 & 54 & TVT & none & N/A & yes & $>100$ & TVT & 14 & $\begin{array}{l}\text { post } \\
\text { repair }\end{array}$ & no & 33 \\
\hline 9 & $79 * *$ & TOT & $\begin{array}{l}\text { ant/post } \\
\text { repair }\end{array}$ & N/A & yes & $<60$ & TVT & 4 & none & no & 6 \\
\hline 10 & 69 & TVT & none & 2 & yes & $60-100$ & TVT & 29 & none & yes & 6 \\
\hline
\end{tabular}

TVT = tension-free vaginal tape/retropubic midurethral synthetic sling; TOT = transobturator tape; MUS = mid-urethral synthetic sling; ant $=$ anterior $;$ post $=$ posterior $;$ antichol $=$ anticholinergic medication; $N / A=$ not applicable; $* *$ failed patients.

loss and operative time for all ten patients was 22 $\mathrm{mL}$ and 50 minutes, respectively. No intraoperative or immediate postoperative complications occurred for any patients.

All 10 women completed the mailed ICIQ (Table-2). Four of the $10(40 \%)$ patients achieved complete urinary continence indicated by a sum score of 0 for the ICIQ. Seven of the 10 women $(70 \%)$ self reported a score of either 0 or 1 on question 3 of the ICIQ, thereby indicating that urine leakage no longer impacted their quality of life. Three patients were not significantly improved by their second procedure.

All three women that did not improve with TVT placement were immediate failures, exhibiting SUI following the initial procedure. Therefore, none of the three patients required incision or removal of the initial midurethral synthetic sling material.
Three of the ten patients use anticholinergics for overactive bladder-type symptoms. Each indicated on the incontinence questionnaire that urine leaks prior to getting to the toilet. However, all three women used anticholinergics prior to the TVT insertion, indicating that the second procedure did not result in de novo detrusor overactivity.

Only one patient had difficulty with bladder emptying after her second surgery. She underwent midurethral sling lysis following her initial TVT due to urinary retention. However, after initial TVT takedown her urinary incontinence was severe and adversely impacted her quality of life. The patient elected to undergo repeat TVT with the understanding that, as her preoperative urodynamics had suggested inefficient voiding, and may require CIC. Following the repeat TVT, the patient experienced no urinary 
Table 2 - ICIQ patient responses.

\begin{tabular}{lccc}
\hline Patient & \multicolumn{2}{c}{ Question } \\
& 1 & 2 & 3 \\
\hline 1 & 0 & 0 & 0 \\
2 & 2 & 2 & 1 \\
3 & 0 & 0 & 0 \\
4 & 1 & 2 & 1 \\
5 & 4 & 2 & 5 \\
6 & 0 & 0 & 0 \\
7 & 5 & 4 & 5 \\
8 & 2 & 2 & 0 \\
9 & 5 & 6 & 10 \\
10 & 0 & 0 & 0 \\
\hline
\end{tabular}

Questions:

1. How often do you leak urine? (range, 0-5)

2. How much urine do you usually leak? (options: 0 none, 2 small amount, 4 moderate amount, 6 large amount)

3. Overall, how much does leaking urine interfere with your everyday life? (range, 0-10)

leakage and indicated satisfaction with the outcome despite the need to perform CIC.

\section{COMMENTS}

Placement of a midurethral synthetic sling has become one of the preferred therapeutic modalities for the surgical management of female SUI. Despite reports of excellent outcomes with TVT placement, some women continue to experience persistent or develop recurrent SUI (1-3). The etiology of persistent or recurrent SUI following TVT is not well defined. Some theorize that the initial placement of the tape was too loose or positioned incorrectly, thereby preventing functional urethral kinking to occur during periods of increased abdominal pressure (17). Riachi et al. proposed that inappropriate intraoperative adjustment of the tape, failure of the tape to be fixed in place, or that the underlying pathology of the urinary incontinence mechanism was responsible for persistent SUI following TVT (13).

There are several surgical treatment choices for the management of SUI following a failed MUS procedure. Such options include placement of an artificial urinary sphincter $(5,6)$, injection of periurethral bulking agents (6), or traditionally a more invasive anti-incontinence procedure such as colposuspension or placement of a suburethral sling (6-8). More recently some authors have advocated possible salvage options following a failed MUS procedure. These maneuvers include transvaginal shortening or readjustment of the implanted tape (9-12). Lo et al. presented, to our knowledge, the largest reported case series for treatment of recurrent SUI after a TVT procedure by shortening the pre-implanted tape under local anesthesia. Using this method they report a greater than $70 \%$ subjective and objective cure rate in 14 women (9). The main limitation of this technique, however, is the need to identify and dissect the tape free from adherent periurethral tissue. For example, Tsivian et al. reoperated on 12 women for SUI following failed MUS placement. During the surgery, the prior MUS could not be found in three women, and was embedded and unable to be dissected free in another (14). Similarly, Riachi et al. could not identify the previously placed tape in 1 of 2 women undergoing reoperation for recurrent SUI following an initial TVT procedure (13), and Villet et al. reported the failure to locate the previously placed synthetic sling in 1 of 3 women (10). If the tape was initially placed incorrectly, shortening would not improve the results. Therefore, despite the apparent efficacy of the transvaginal TVT tape shortening procedure for recurrent SUI, it requires the identification and subsequent periurethral dissection of the previously placed tape, which may prove to be difficult. We made no attempt to locate or alter the previously placed tape in our patients in order to minimize the periurethral dissection.

Another option for surgical management of a failed MUS procedure is to repeat the procedure, thereby eliminating any manipulation of the previously placed tape. Riachi et al. first described repeat application of a TVT in two patients at 8 and 9 months after the initial procedure. Both women were completely continent at 6 and 13 month follow-up (13). Villet et al. reported on two patients who underwent repeat TVT, no complications were reported and each woman was continent at four and 12 months of followup (10). In addition to these case reports, Tsivian et al. presented a case series of 12 women who underwent 
repeat MUS for persistent or recurrent SUI following a previous MUS procedure. They report that 11 of 12 patients achieved full continence following repeat surgery. Interestingly, five patients underwent repeat TVT, four underwent intravaginal sling, and three underwent TOT placement. Unfortunately the authors did not utilize urodynamic evaluation nor present their telephone acquired questionnaire results for post-operative objective or subjective assessment (14). Recently, Moore et al. reported on the successful treatment of five women with recurrent SUI using a TVT following a failed prior TOT insertion (15). The largest series of repeat TVT has been reported by Lee et al. (16), who report similar results. They used both retropubic and transobturator approaches and noted significantly better cure rates with the retropubic approach.

In our series, 10 women underwent retropubic TVT for the management of SUI following a failed previous MUS procedure. Using the ICIQ, four women $(40 \%)$ reported complete urinary continence, whereas another three women $(30 \%)$ reported significant improvement in their quality of life. Three women did not improve following repeat TVT placement. The average age of these three women was 12 years greater than the four patients who became completely continent following repeat TVT, and two of the three women exhibited VLPP $<60 \mathrm{~cm} \mathrm{H}_{2} \mathrm{O}$ on preoperative video urodynamic evaluation. The results in this subset of patients are not surprising since patients with low VLPP have been shown to demonstrate lower cure rates following MUS procedures than patients with VLPP $>60$ $\mathrm{cm} \mathrm{H}_{2} \mathrm{O}(18,19)$. Moreover, elderly patients have been shown to report decreased improvement following antiincontinence procedures when compared to a younger cohort undergoing comparable surgeries (20).

Further analysis of the data showed no substantial difference in outcome between the five patients who underwent initial TOT in comparison to the five patients who had initial TVT placement. For those women with initial TOT placement, subsequent TVT resulted in two of the five becoming completely continent and three of the five indicating that urine leakage no longer impacted their quality of life. Similarly, for the patients who underwent TVT placement a second time, two became completely continent and four expressed that urine leakage no longer impacted their quality of life. The number of cases is too small to make definitive conclusions or meaningful statistical analysis.

All four of the patients who had undergone tape incision, did well, two were completely dry and two had minimal unbothersome leakage.

Advantages for performing TVT following a previously unsuccessful MUS include its minimally invasive nature, rapid patient recovery, and reported efficacy. As compared to transvaginal retensioning of the previously placed tape, repeat TVT insertion does not require identification of the initial sling material, thereby eliminating the need for any further periurethral dissection. In addition, our findings do not suggest any increased risk of surgical complications (difficulty with needle passage, bladder injury, erosion) when performing TVT placement after a prior unsuccessful MUS procedure. Although a questionnaire was not completed pre-operatively for comparison, the combination of urodynamically demonstrated SUI and the patient's desire to undergo repeat surgery indicates that urinary incontinence substantially impacted their quality of life at that time. A limitation of this study is the lack of objective data such as a pad test. However, we treat patients because they believe they have failed their prior management, not because we think they have failed. We therefore contend that patient-reported outcomes are the most important tool in which to assess the efficacy of this treatment.

\section{CONCLUSIONS}

We present a case series advocating application of the TVT for treatment of recurrent or persistent SUI following an unsuccessful prior MUS. Such an intervention could avoid the more extensive scarring, bleeding and perioperative complications associated with more invasive procedures and does not require additional periurethral dissection for identification of the previously placed material. Despite the shortterm follow-up and small sample size, the results of our study suggest that TVT insertion may be a viable option for the management of failed previous MUS procedures. Further studies with longer follow-up and more patients are necessary to identify the best option for management of recurrent or persistent SUI following a previous MUS procedure. 


\section{CONFLICT OF INTEREST}

\author{
None declared.
}

\section{REFERENCES}

1. Merlin T, Arnold E, Petros P, MacTaggart P, Tulloch A, Faulkner K, et al.: A systematic review of tension-free urethropexy for stress urinary incontinence: intravaginal slingplasty and the tension-free vaginal tape procedures. BJU Int. 2001; 88: 871-80.

2. Lo TS: Tension-free vaginal tape procedures in women with stress urinary incontinence with and without coexisting genital prolapse. Curr Opin Obstet Gynecol. 2004; 16: 399-404.

3. Nilsson CG, Falconer C, Rezapour M: Seven-year follow-up of the tension-free vaginal tape procedure for treatment of urinary incontinence. Obstet Gynecol. 2004; 104: 1259-62.

4. Tsivian A, Mogutin B, Kessler O, Korczak D, Levin S, Sidi AA: Tension-free vaginal tape procedure for the treatment of female stress urinary incontinence: long-term results. J Urol. 2004; 172: 998-1000.

5. Elliott DS, Barrett DM: The artificial urinary sphincter in the female: indications for use, surgical approach and results. Int Urogynecol J Pelvic Floor Dysfunct. 1998; 9: 409-15.

6. Schulz JA, Drutz HP: The surgical management of recurrent stress urinary incontinence. Curr Opin Obstet Gynecol. 1999; 11: 489-94.

7. Amaye-Obu FA, Drutz HP: Surgical management of recurrent stress urinary incontinence: A 12-year experience. Am J Obstet Gynecol. 1999; 181: 1296-307; discussion 1307-9.

8. Petrou SP, Frank I: Complications and initial continence rates after a repeat pubovaginal sling procedure for recurrent stress urinary incontinence. J Urol. 2001; 165: 1979-81.

9. Lo TS, Wang AC, Liang CC, Long CY, Lee SJ: Treatment for unsuccessful tension-free vaginal tape operation by shortening pre-implanted tape. J Urol. 2006; 175: 2196-9; discussion 2199-200.

10. Villet R, Ercoli A, Atallah D, Hoffmann P, Salet-Lizee D: Second tension-free vaginal tape procedure and mesh retensioning: two possibilities of treatment of recurrent-persistent genuine stress urinary incontinence after a primary tension-free vaginal tape procedure. Int Urogynecol J Pelvic Floor Dysfunct. 2002; 13: 377-9.
11. Neuman M: Trans vaginal tape readjustment after unsuccessful tension-free vaginal tape operation. Neurourol Urodyn. 2004; 23: 282-3.

12. Paick JS, Ku JH, Shin JW, Park KJ, Kim SW, Oh SJ: Shortening of tension-free vaginal tape for the treatment of recurrent incontinence. J Urol. 2004; 171: 1634.

13. Riachi L, Kohli N, Miklos J: Repeat tension-free transvaginal tape (TVT) sling for the treatment of recurrent stress urinary incontinence. Int Urogynecol J Pelvic Floor Dysfunct. 2002; 13: 133-5; discussion 135.

14. Tsivian A, Neuman M, Yulish E, Shtricker A, Levin S, Cytron S, Sidi AA: Redo midurethral synthetic sling for female stress urinary incontinence. Int Urogynecol J Pelvic Floor Dysfunct. 2007; 18: 23-6.

15. Moore RD, Gamble K, Miklos JR: Tension-free vaginal tape sling for recurrent stress incontinence after transobturator tape sling failure. Int Urogynecol J Pelvic Floor Dysfunct. 2007; 18: 309-13.

16. Lee KS, Doo CK, Han DH, Jung BJ, Han JY, Choo MS: Outcomes following repeat mid urethral synthetic sling after failure of the initial sling procedure: rediscovery of the tension-free vaginal tape procedure. J Urol. 2007; 178: 1370-4; discussion 1374.

17. Nitti V: Editorial comment. J Urol. 2006; 175: 2199200.

18. Paick JS, Ku JH, Shin JW, Son H, Oh SJ, Kim SW: Tension-free vaginal tape procedure for urinary incontinence with low Valsalva leak point pressure. J Urol. 2004; 172: 1370-3.

19. O'Connor RC, Nanigian DK, Lyon MB, Ellison LM, Bales GT, Stone AR: Early outcomes of mid-urethral slings for female stress urinary incontinence stratified by valsalva leak point pressure. Neurourol Urodyn. 2006; 25: 685-8.

20. Hellberg D, Holmgren C, Lanner L, Nilsson S: The very obese woman and the very old woman: tensionfree vaginal tape for the treatment of stress urinary incontinence. Int Urogynecol J Pelvic Floor Dysfunct. 2007; 18: 423-9.

Accepted after revision:

March 21, 2008

\footnotetext{
Correspondence address:

Dr. Jonathan A. Eandi

Department of Urology

UC Davis Medical Center

4860 Y Street, Suite 3500

Sacramento, CA, 95817, USA

Fax: + 1916 734-8094

E-mail: jonathan.eandi@ucdmc.ucdavis.edu
} 
Appendix-1

International Consultation on Incontinence Questionnaire (ICIQ)

1. How often do you leak urine? (Pick one box)

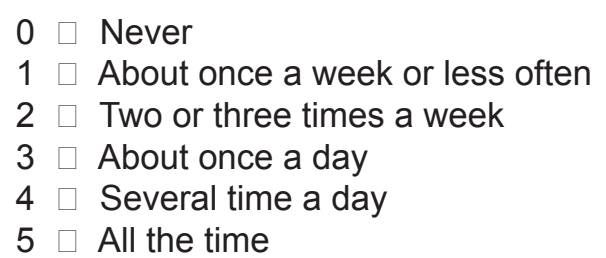

We would like to know how much you think leaks?

2. How much urine do you usually leak (whether you wear protection or not)?

(Pick one box)
$0 \square$ None
$2 \square$ A small amount
$4 \square$ A moderate amount
$6 \square$ A large amount

3. Overall, how much does leaking urine interfere with your everyday life? (Please ring a number between 0 (not at all) and 10 (a great deal)

$\begin{array}{lrllllllll}0 & 1 & 2 & 3 & 4 & 5 & 6 & 7 & 8 & 9 \begin{array}{c}10 \\ \text { not at all }\end{array}\end{array}$

4. When does urine leak? (Please pick all that apply to you)
Never - urine does not leak
Leaks before you can get to the toilet
Leaks when you cough or sneeze
Leaks when you are asleep
Leaks when you are physically active/exercising
Leaks when you have finished urinating and are dressed
Leaks for no obvious reason
Leaks all the time 


\section{EDITORIAL COMMENT}

With current understanding of pathophysiology of stress urinary incontinence (SUI), integral mid-urethra theory explains most of its occurrence and has enabled successful introduction of minimally invasive mid-urethral tension-free tapes with success rates over $80 \%$. However, pathophysiology of the unfortunate $20 \%$ patients who failed the initial surgery needs attention. The factors for recurrence include, not exclusively, so-called intrinsic sphincter deficiency (ISD) of varied etiology, voiding dysfunction and overactive bladder, and have a great bearing on further management as well as counseling of these low-on-self esteem patients. This underscores the importance of detailed evaluation of these patients before planning surgical management.

The present study is a retrospective analysis of 10 cases with recurrent SUI following midurethral sling (TVT / TOT) and presents encouraging results of TVT in this subgroup. I would congratulate the authors for performing a detailed preoperative evaluation of all these patients including clinico-urodynamic evaluation, appropriate management of overactive bladder and adequate counseling (which led to a satisfied patient even on CIC). Management of recurrent SUI is not standardized and the authors are justified in their approach due to minimally invasive nature of the procedure. TVT has been reported as a viable treatment option for recurrent SUI after MUS as well as other surgical procedures.

Apart from the main conclusion, there are various 'hidden' important results in this article which need emphasis and are worthy of further investigations. ISD is a well known subgroup of SUI and is vaguely defined as severe incontinence, absence of urethral hypermobility (UH), open bladder neck (resulting from previous surgery, radiotherapy, old age, etc.), Valsalva leak point pressure $<60 \mathrm{~cm}$ $\mathrm{H}_{2} \mathrm{O}$ and maximal urethral closure pressure $<20$ $\mathrm{cm} \mathrm{H}_{2} \mathrm{O}$. There are several reports to suggest lower, though clinically significant, success rates of MUS (especially TOT) in these patients more so in absence of UH. In the present study, two of three women who failed the repeat procedure had a Valsalva leak point pressure $<60 \mathrm{~cm} \mathrm{H}_{2} \mathrm{O}$; it would be interesting to know degree of hypermobility and preoperative degree of incontinence in these patients. Although far from standard, it seems plausible to opt for some alternative form of treatment, e.g. injection therapy or compressive slings at bladder neck level in case of more than one 'risk factors' of ISD, especially absence of UH.

Voiding dysfunction (VD) has been reported to be more common after TVT than TOT, though the data on latter is limited. Four of the 10 analyzed patients had had release of tape for voiding dysfunction leading to recurrent SUI; interestingly 3 of these had undergone TVT, and one TOT. It would be desirable to report the incidence of VD after each procedure in their experience. Furthermore, pre-existing voiding dysfunction and urethral relaxation voiding patterns (with detrusor pressure $<12 \mathrm{~cm} \mathrm{H}_{2} \mathrm{O}$ ) have been reported to be risk-factors for postoperative urinary retention and need for release of sling after TVT. Therefore, it would be worthwhile to report voiding function and voiding mechanism in these women.

I believe we have reached a stage where our focus should shift to standardizing the management of recurrent SUI. A practical approach to produce preliminary guidelines would be to perform some sort of meta-analysis of the existing case series and then to formulate plans of prospective randomized trials comparing various strategies.

\section{Dr. Mayank Mohan Agarwal Dr. Ravimohan Mavuduru} Section of Urology

Postgraduate Institute of Medical Education and Research Chandigarh, India E-mail:drmayank_22@yahoo.co.in 


\section{EDITORIAL COMMENT}

The authors present their experience with redo tension -free transvaginal tape placement for the management failed midurethral sling (MUS). MUS procedure has gained wide acceptance for the treatment of female urinary stress incontinence. However, failure rate ranges between 5 to $20 \%$ (ref .3,4 of the reviewed manuscript) and with the widespread use of this technique, the practicing surgeon will encounter a considerable number of failures.

What should be the optimal management of MUS failure? There is scarce data in the literature, therefore, in spite of the small series and short-term follow up, lack of objective data (physical exam, stress test, pad test etc) presented herein, this manuscript offers well-timed and important contribution in data accumulation and improvement of our understanding in resolving this problem.

One should note, that the preoperative work-up of MUS failure should include cystoscopy to exclude tape erosion into the bladder or/and urethra, especially in patients with irritative voiding symptoms.

Additional, well designed comparative studies are warranted to answer questions such as optimal timing of the salvage procedure, and whether repeat MUS should be applied or different approach is appropriate, and if MUS is chosen what is the preferred route, -transobturator or retropubic?

Dr. Alexander Tsivian Department of Urologic Surgery The E. Wolfson Medical Center, Holon Sackler Faculty of Medicine, Tel Aviv University Tel Aviv, Israel E-mail:atsivian@hotmail.com 